\title{
Quadricuspid aortic valve: Surgical repair with aortic root reimplantation in an adult
}

\author{
Stephanie L. Perrier, MD, Philippe Billaud, MD, Michel Kindo, MD, PhD, and \\ Jean Philippe Mazzucotelli, MD, PhD, Strasbourg, France
}

\footnotetext{
From the Cardiovascular Surgery Department, University Hospital of Strasbourg, Strasbourg, France. Disclosures: Authors have nothing to disclose with regard to commercial support.

Received for publication Oct 28, 2019; revisions received Oct 28, 2019; accepted for publication Nov 29, 2019; available ahead of print Feb 3, 2020.

Address for reprints: Stéphanie L. Perrier, MD, Service de chirurgie cardiovasculaire, Nouvel Hôpital Civil, Hôpitaux Universitaires de Strasbourg, 1 place de l'hôpital, 67000 Strasbourg, France (E-mail: stephanie. perrier@chru-strasbourg.fr).

JTCVS Techniques 2020;1:28-30

2666-2507

Copyright (C) 2020 The Author(s). Published by Elsevier Inc. on behalf of The American Association for Thoracic Surgery. This is an open access article under the CC BY-NC-ND license (http://creativecommons.org/licenses/bync-nd/4.0/).

https://doi.org/10.1016/j.xjtc.2019.11.010
}

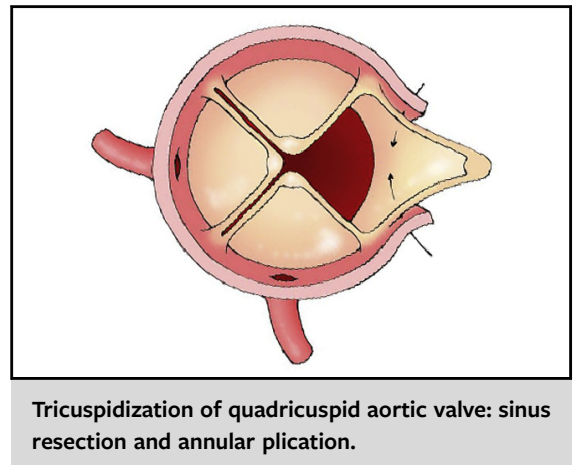

CENTRAL MESSAGE

The technique described allows successful tricuspidization of severely regurgitant type $A$ quadricuspid aortic valve by aortic sinus resection, annular plication, and approximation of commissures.

See Commentaries on pages 31 and 32.
Quadricuspid aortic valve is rare, leading mostly to aortic regurgitation. ${ }^{1}$ We present herein an original technique, in association with aortic root reimplantation, for the repair of a severely regurgitant quadricuspid aortic valve with dilated aortic root.

\section{CASE REPORT}

A 39-year-old man with history of systemic hypertension treated with angiotensin-converting enzyme inhibitors, depression, moderate tobacco and alcohol use, presented with New York Heart Association stage II or III dyspnea and asthenia. A diastolic murmur was noted. Transthoracic and transesophageal echocardiography showed severe aortic valve regurgitation (Figure $1, A$ ) resulting from central coaptation defect (Figure $1, B$ ). The aortic valve had 4 cusps of equivalent size (Hurwitz classification type $\mathrm{A}^{2}$ ) (Figure 1, $C$ and $D$ ). The aortic root, sinotubular junction, and ascending aorta $(44 \mathrm{~mm}, 43 \mathrm{~mm}$, and $43 \mathrm{~mm}$, respectively) and left ventricle were dilated (left ventricular end diastolic diameter, $70 \mathrm{~mm}$ ). Left ventricular ejection fraction was $50 \%$. Cardiac magnetic resonance imaging confirmed these findings (Figure 1,D). He was thus referred for surgery. Surgical repair was undertaken through median sternotomy with cardiopulmonary bypass between the aorta and the right atrium (208 minutes) with intermittent retrograde cold blood cardioplegia through coronary sinus. Aortic crossclamp time was 165 minutes. The ascending aorta was transected. All 4 cusps were thin and pliable, and of equivalent size (Figure 2, $A$ ). The right-sided, more posterior, accessory noncoronary cusp was prolapsing. The corresponding posterior accessory sinus of Valsalva was longitudinally opened through to the aortic annulus (Figure 2, B). The sinus wall was resected. Both commissures were approximated, the aortic annulus was plicated, and aortic root was reconstructed with interrupted pledgeted sutures reinforced with continuous 4-0 polypropylene suture, incorporating the excluded cusp in the suture, using it as mattress tissue (Figure 2, B) (Video 1). Coaptation of tricuspidized aortic valve was satisfactory (Figure 2,C). Standard root reimplantation was performed with a 26$\mathrm{mm}$ Cardioroot prosthesis (Intervascular SAS, La Ciotat, France). Intraoperative transesophageal echocardiography showed satisfactory valvular function. Patient was extubated 4 hours after surgery. The postoperative course was uncomplicated. Histopathology of the aortic wall was normal without inflammation or fibromuscular necrosis. The patient was discharged home on postoperative day 4 


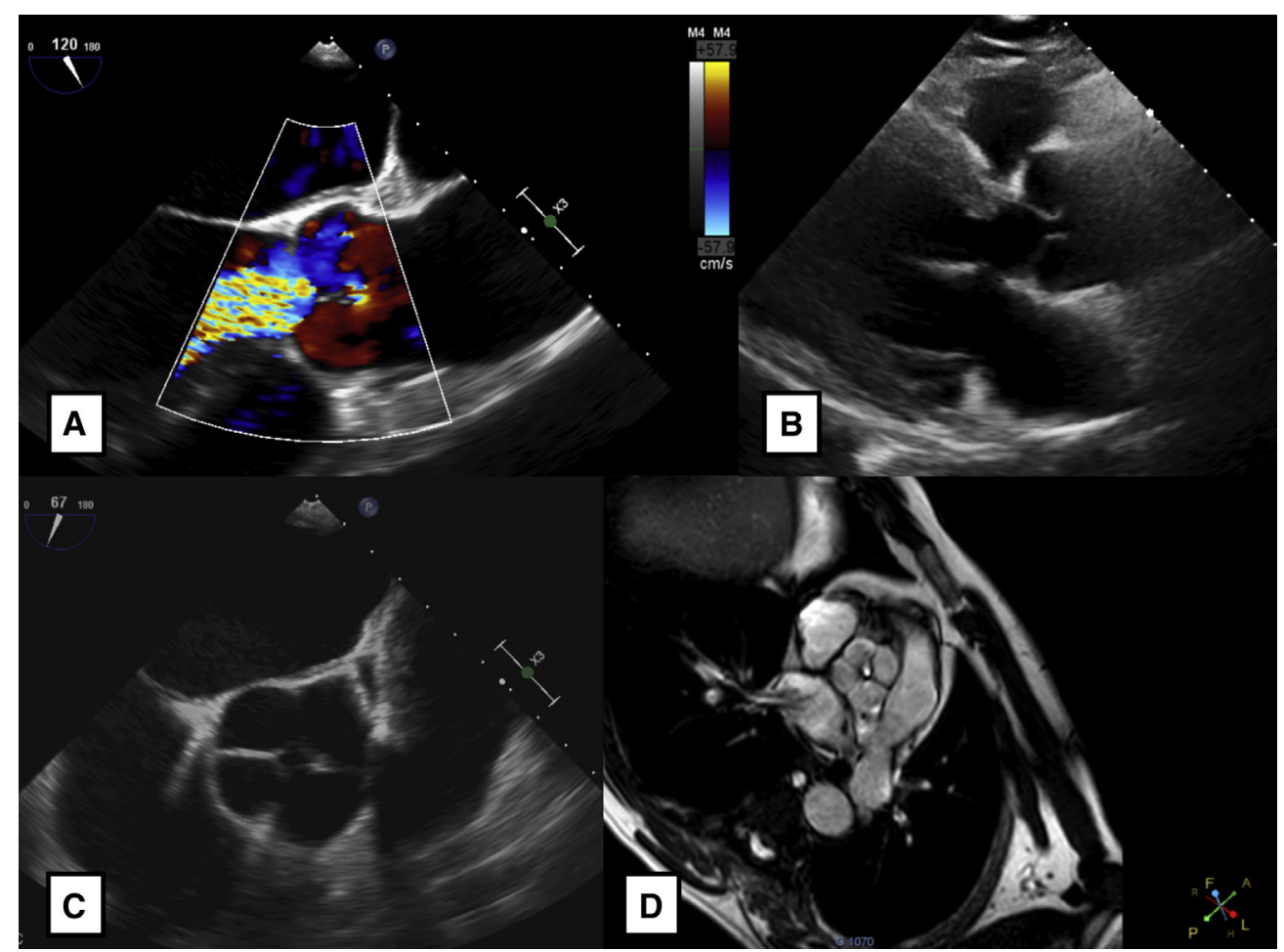

FIGURE 1. A, Preoperative transesophageal echocardiography long axis view. A, Showing severe aortic regurgitation. B, Showing coaptation defect. Four aortic leaflets of equivalent size are identified. C, Shown on transesophageal echocardiography short axis view. D, Shown on cardiac magnetic resonance imaging.

with trivial aortic regurgitation, preserved left ventricular function, and mean aortic valve pressure gradient of $12 \mathrm{~mm} \mathrm{Hg}$. Four months postoperatively, he was asymptomatic with left ventricular ejection fraction of $60 \%$, reduced left ventricular end diastolic diameter $(54 \mathrm{~mm})$, and only trivial aortic regurgitation without stenosis.

\section{COMMENT}

Quadricuspid aortic valve is rare with less than $0.05 \%$ of estimated prevalence. ${ }^{1}$ Mean age at diagnosis is around 40 years; about $90 \%$ of patients have aortic regurgitation. ${ }^{1}$ It has been shown that at least one third of these patients have aortic root and/or ascending aorta dilatation. ${ }^{1}$ To date, there is no evidence whether aortic dilatation is genetically or hemodynamically mediated. In our case, neither histologic anomaly nor history of other congenital heart disease, genetic disorders, or connective tissue disorders were present. Nevertheless, quadricuspid valve morphology is associated with altered aortic hemodynamic performance compared with trileaflet aortic valves.

Patients with quadricuspid aortic valve are usually referred for surgical intervention around age 30 years because of aortic regurgitation associated with aortic root and/or ascending aorta dilatation. ${ }^{1}$ Surgical repair is not only feasible, but also an even better option than prosthetic replacement for these young patients. Several techniques of tricuspidization have been described according to valvular anatomy: detachment of rudimentary commissure, triangular resection and reconstruction with patch, or suturing rudimentary and smaller cusps together. ${ }^{4}$ In the case of type A quadricuspid aortic valve, these techniques would result in a highly unbalanced trileaflet valve with 2 smaller cusps and a larger cusp. Also, early reoperation for severe regurgitation due to dehiscence of neocusp sutures has been described. ${ }^{5}$ The technique we describe herein is easily reproducible and allows diameter reduction of a dilated aortic root. The aortic annulus is further stabilized by aortic root reimplantation. Although long-term outcomes are yet to be known, early results of this technique are promising. This tricuspidization procedure could find a useful place in the armamentarium of cardiac surgeons dealing with dysfunctional quadricuspid aortic valves.

\section{References}

1. Tsang MYC, Abudiab MM, Ammash NM, Naqvi TZ, Edwards WD, Nkomo VT, et al. Quadricuspid aortic valve: characteristics, associated structural cardiovascular abnormalities, and clinical outcomes. Circulation. 2016;133:312-9.

2. Hurwitz LE, Roberts WC. Quadricuspid semilunar valve. Am J Cardiol. 1973;31 623-6.

3. Entezari P, Schnell S, Mahadevia R, Malaisrie C, McCarthy P, Mendelson M, et al From unicuspid to quadricuspid: influence of aortic valve morphology on aortic three-dimensional hemodynamics. J Magn Reson Imaging. 2014;40:1342-6.

4. Mastrobuoni S, Aphram G, Tamer S, Navarra E, De Kerchove L, El Khoury G. Quadricuspid aortic valve repair. Ann Cardiothorac Surg. 2019;8:433-5.

5. Ohira S, Doi K, Yamano T, Yaku H. Early failure of quadricuspid aortic valve tricuspidization due to dehiscence of approximating coronary cusps. J Echocardiogr. 2014; $12: 75-7$. 
A
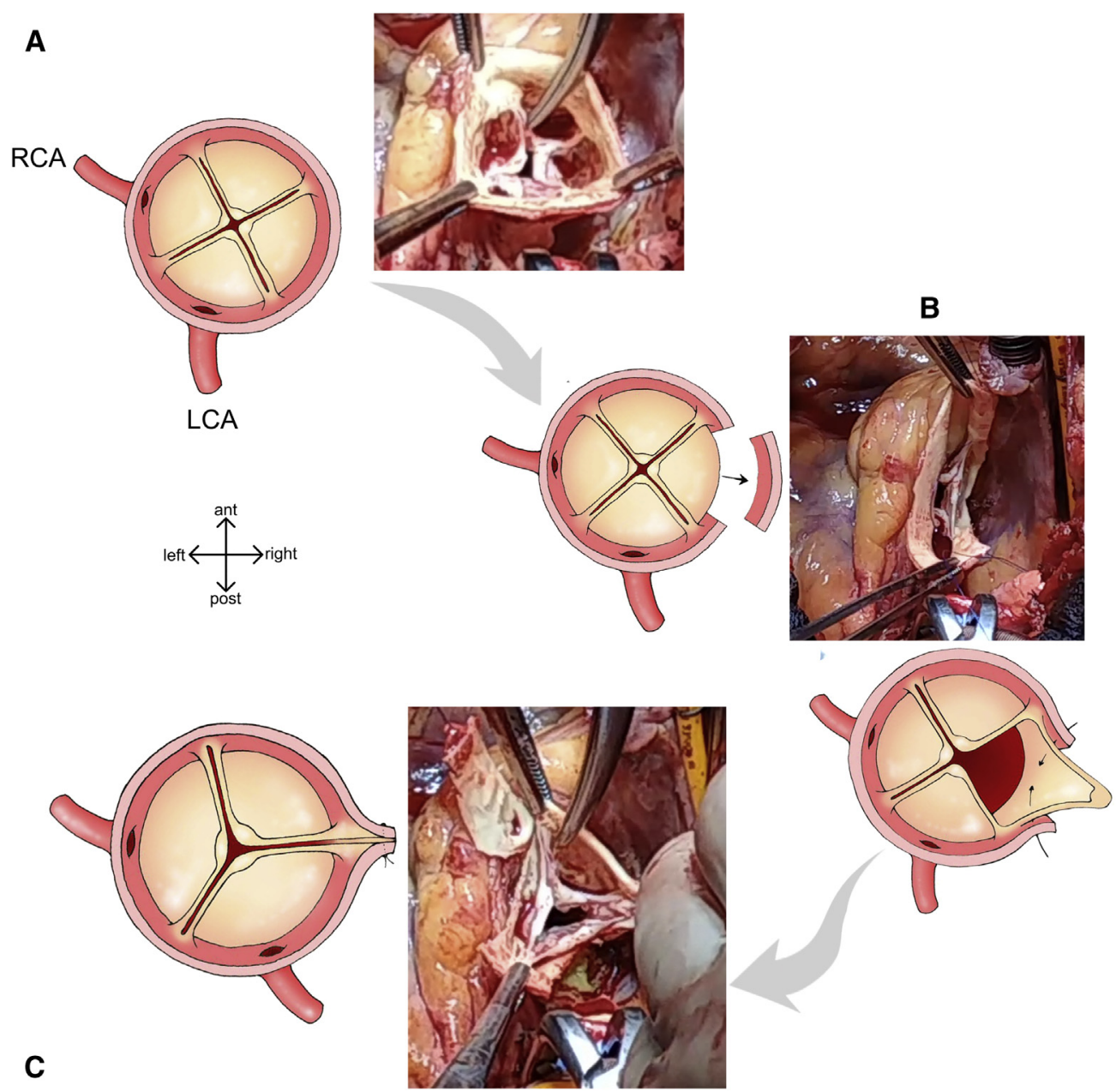

FIGURE 2. Tricuspidization operative technique: Quadricuspid aortic valve exposed after transection of the aorta, with 4 equivalent-size leaflets. A, One right coronary artery $(R C A)$ sinus, 1 left coronary artery $(L C A)$ sinus and 2 noncoronary sinuses. B, Posterior (post) noncoronary aortic sinus, adjacent to the left coronary sinus, is resected. C, Corresponding commissures, shown by both forceps, are approximated with plication of the aortic annulus, including the leaflet in the suture for reinforcement, resulting in a trileaflet valve. ant, Anterior.

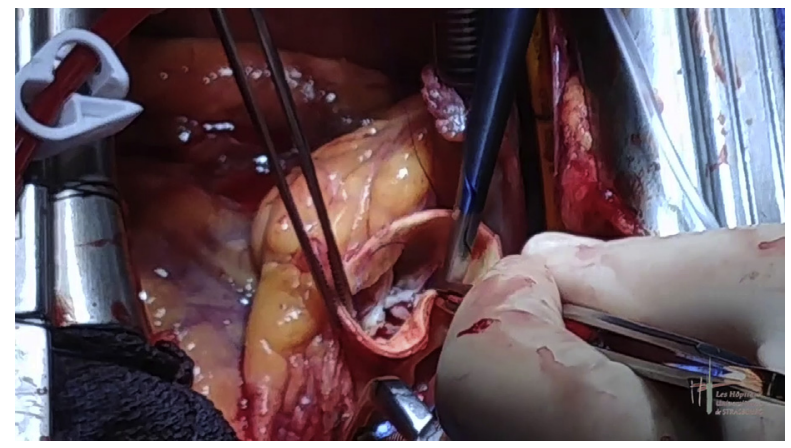

VIDEO 1. Operative technique for tricuspidization of quadricuspid aortic valve. Video available at: https://www.jtcvs.org/article/S2666-2507(20) 30009-2/fulltext. 